Ensino, Saúde e Ambiente - V5 (2), pp. $198-210$, ago. 2012

\title{
EDUCAÇÃO AMBIENTAL NO CONTEXTO DO ENSINO DE CIÊNCIAS:
}

\section{UM ESTUDO DE REVISÃO}

\author{
ENVIRONMENTAL EDUCATION IN THE CONTEXT OF SCIENCE \\ TEACHING: A REVIEW STUDY \\ André da Silva Brites ${ }^{1}$ e Ivone Evangelista Cabral ${ }^{1}$ \\ ${ }^{1}$ Universidade Federal do Rio de Janeiro \\ ${ }^{1}$ Núcleo de Tecnologia Educacional para a Saúde (NUTES) \\ brites84@gmail.com \\ icabral44@hotmail.com
}

RESUMO: Este estudo investigou os trabalhos científicos de Educação Ambiental (EA) inseridos no contexto do ensino de Ciências no período de 2005 a 2011, no sentido de aproximar ainda mais este tema, uma vez que a concepção de ambiente no ensino de Ciências desempenha um papel central no desenvolvimento desta disciplina escolar. Foram consultados os periódicos "Investigações no ensino de ciências" e "Ciência e Educação", através do Portal de Periódicos da CAPES, além da BVS (Biblioteca Virtual de Saúde). A EA vem se destacando no campo da pesquisa de maneira inter e pluridisciplinar, podendo, além disso, servir de base para a criação de projetos políticopedagógicos que auxiliem no debate de questões socioambientais e contribuam para uma educação comprometida com o desenvolvimento sustentável. Percebe-se ainda uma preocupação em associar educação ambiental às atividades de ensino de ciências e integrar esse tema na prática pedagógica dos professores, respeitando-se o contexto dos alunos.

Palavras-chave: educação ambiental; ensino de ciências; escola.

\begin{abstract}
This study investigated published environmental education articles inserted in the context of Science teaching (2005-2011) to approach this object of investigation, because the environmental conception develops a great paper in Science teaching. There were researched these periodic 'Science Teach Investigations' and 'Science and Education' and BVS (Health Virtual Library). Environmental education has been grown up in the field of research inter and plural disciplinarily. Besides that could base political and pedagogic projects, that helps to debate social and environmental questions and contributes to sustainable education development. There is a worry about the association between environmental education and science teaching activities to integrate this theme in the teacher's pedagogical practice respecting the context of the students.
\end{abstract}

Key Words: environmental education; science teach; school.

\section{INTRODUÇÃO}

A educação se configura como uma prática social e politicamente compromissada, que visa garantir os processos de sociabilidade e a construção de relacionamentos entre a sociedade e a natureza e entre os diferentes seres humanos. 
Devido ao seu caráter complementar e transdisciplinar, a Educação Ambiental (EA) aparece também no campo do ensino de ciências. A opção pela análise da temática educação ambiental no âmbito do ensino de ciências surge pela necessidade de aproximar ainda mais este tema de investigação, uma vez que a concepção de ambiente no ensino de Ciências desempenha um papel central no desenvolvimento desta disciplina escolar.

Segundo Rodrigues (2009), o ensino de ciências não deve mais ser visto como uma transmissão de conceitos, mas sim como uma construção de conhecimentos para que o processo ensino-aprendizagem tenha sentido e contextualidade. Para Guimarães e Vasconcellos (2006, p.7) "o enfrentamento da atual crise socioambiental depende, entre outras, da luta pela formulação de uma ciência e uma cultura engajadas no processo de construção de um modelo de sociedade ecológica e socialmente sustentável". Deste modo, as escolas se destacam por representarem espaços de diálogo e promoção de práticas educativas que podem contribuir para a formação de sujeitos ecológicos como defendido por Carvalho (2011, p. 151) "a educação ambiental tem uma proposta ética de longo alcance que pretende reposicionar o ser humano no mundo, convocando-o a reconhecer a alteridade da natureza e a integridade e o direito à existência não utilitária do ambiente".

A escola deve proporcionar à população infantil elementos de conhecimentos, procedimentos e atitudes que lhes permitam situar-se na sociedade de consumo de uma maneira consciente, crítica, responsável e solidária (DAMASIO; SAMPAIO, 2003). Os autores também defendem uma organização concreta no currículo das áreas para tratar da temática do consumismo em torno de um eixo educativo, uma vez que o mesmo está proposto como tema transversal dos Parâmetros Curriculares Nacionais. Fracalanza (2004, p.7) defende que a educação ambiental nas escolas deve se aproximar de uma "atividade contínua; com caráter interdisciplinar; com um perfil pluridimensional; voltada para a participação social e para a solução de problemas ambientais; visando a mudança de valores, atitudes e comportamentos sociais". Em estudo sobre a aplicação de oficinas de materiais recicláveis no ensino de ciências e em programas de educação ambiental, Campos e Cassavan (2007 apud BARROS e PAULINO, 1997; CRUZ, 1997) destacam que o lixo é apresentado em alguns livros didáticos do ensino de ciências em capítulos relacionados ao saneamento básico e à saúde pública e, como notas de educação ambiental nas margens de capítulos, contendo propostas de reutilização de materiais recicláveis. Porém, isto é realizado de modo superficial sem questionar a 
origem dos materiais, além de aspectos relacionados ao aumento do consumo exagerado.

A problemática ambiental passa historicamente pela revolução industrial, a qual trouxe consigo o desenvolvimento e a manutenção de estruturas que fossem capazes de suportar padrões de consumo e bem estar sociais impostos pelo capitalismo. Na medida em que os efeitos da degradação ambiental tornam-se visíveis aos olhos de todos e traz conseqüências para a vida das pessoas no cotidiano, há um despertar gradual da sociedade para uma consciência ambiental. Nesse sentido, a degradação ambiental, inicialmente concentrada próximo ao seu agente causador, passou a ter uma abrangência maior. A consciência sobre a incerteza e irreversibilidade dos impactos, não foi suficiente para eliminá-los, mas foi capaz de sinalizar os limites antes que as conseqüências fossem irreversíveis e catastróficas. $\mathrm{O}$ surgimento de uma conscientização ambiental crescente vem revelando um enorme potencial para provocar mudanças nos padrões de produção e consumo. Portanto, a educação ambiental se configura uma estratégia fundamental para a formação de uma consciência cidadã para o gerenciamento adequado e sustentável dos resíduos sólidos, bem como um instrumento para a reflexão das pessoas sobre a mudança de atitudes em relação ao correto descarte do lixo e a preservação do meio ambiente (GUSMÃO, 2000).

\title{
ABORDAGEM METODOLÓGICA
}

O presente trabalho tem por objetivo realizar um mapeamento das produções científicas de educação ambiental no contexto do ensino de ciências no período de 2005 a 2011. Segundo Ferreira (2002), as pesquisas de cunho bibliográfico despertam a curiosidade dos pesquisadores acerca da totalidade de estudos e pesquisas em determinada área de conhecimento:

\begin{abstract}
Nos últimos quinze anos tem se produzido um conjunto significativo de pesquisas conhecidas pela denominação "estado da arte" ou "estado do conhecimento". Definidas como de caráter bibliográfico, elas parecem trazer em comum o desafio de mapear e de discutir certa produção acadêmica em diferentes campos do conhecimento, tentando responder que aspectos e dimensões vêm sendo destacados e privilegiados em diferentes épocas e lugares, de que formas e em que condições têm sido produzidas certas dissertações de mestrado, teses de doutorado, publicações em periódicos e comunicações em anais de congressos e de seminários. (FERREIRA, 2002, p.2)
\end{abstract}

Para isso, foram consultados os seguintes periódicos: Investigações no Ensino de Ciências (IEC) e Ciência e Educação (C\&Ed), acessados através do Portal de Periódicos 
da CAPES (http://www.periodicos.capes.gov.br/), conforme descrito na Tabela 1, além da BVS (Biblioteca Virtual de Saúde), utilizando a base de dados LILACS. Os critérios de inclusão seguiram: artigos no idioma português, que continham as palavras/expressões "educação ambiental"; "ensino de ciências" e/ou "escola" nos títulos, resumos ou palavras-chave, compreendidos no período de 2005 a 2011.

\section{APRESENTAÇÃO DOS RESULTADOS}

No Portal de Periódicos da CAPES, foram realizados dois tipos de busca nos periódicos IEC e C\&Ed, respectivamente: busca avançada e busca por área de conhecimento. A tabela 1 apresenta a distribuição quantitativa dos 26 artigos encontrados que tratavam da temática educação ambiental no contexto do ensino de ciências, no período de 2005 a 2011:

Tabela 1. Distribuição dos artigos sobre EA pesquisados nos periódicos de Ensino de Ciências

\begin{tabular}{cccccccccc}
\hline \multirow{2}{*}{ Periódico } & \multicolumn{8}{c}{ Ano de Publicação } & \multirow{2}{*}{ Total } \\
\cline { 2 - 8 } & $\mathbf{2 0 0 5}$ & $\mathbf{2 0 0 6}$ & $\mathbf{2 0 0 7}$ & $\mathbf{2 0 0 8}$ & $\mathbf{2 0 0 9}$ & $\mathbf{2 0 1 0}$ & $\mathbf{2 0 1 1}$ & \\
\hline \hline IEC & 0 & 0 & 0 & 1 & 0 & 0 & 1 & 2 \\
\hline Total de Publicações & 17 & 18 & 18 & 18 & 24 & 24 & 24 & 143 \\
\hline C\&Ed & 1 & 1 & 4 & 7 & 2 & 6 & 3 & 24 \\
\hline Total de Publicações & 36 & 24 & 28 & 39 & 39 & 45 & 60 & 271 \\
\hline
\end{tabular}

\section{Investigações no Ensino de Ciências (IEC)}

Foi realizada uma busca avançada no campo "buscar periódico" preenchido com a expressão "ensino de ciências" e selecionada a área do conhecimento "ciências biológicas". O resultado apontou apenas um registro, o periódico "Investigações em Ensino de Ciências" (IEC). Foram pesquisados todos os artigos publicados de 2005 a 2011, totalizando 143 publicações conforme demonstrado acima (Tabela 1). Sendo que apenas $02(1,4 \%)$ corresponderam os critérios de inclusão, contendo as palavras/expressões: educação ambiental, ensino de ciências e/ou escola (Tabela 2). 
Tabela 2. Apresentação dos 02 artigos pesquisados no periódico IEC.

\begin{tabular}{|c|c|c|c|}
\hline Título do Artigo & Autor(es) & Ano & Instituição \\
\hline $\begin{array}{c}\text { Percepção e educação ambiental sobre o } \\
\text { ecossistema Manguezal incrementando as } \\
\text { disciplinas de Ciências e Biologia em escola } \\
\text { pública do Recife-PE }\end{array}$ & $\begin{array}{c}\text { RODRIGUES, L.L. } \\
\text { FARRAPEIRA, C.M.R. }\end{array}$ & 2008 & UFRP \\
\hline $\begin{array}{c}\text { Ensino de Química e Ambiente: As articulações } \\
\text { presentes na revista Química Nova na Escola } \\
\text { (Qnesc) }\end{array}$ & $\begin{array}{c}\text { LATINI, R.M. } \\
\text { SOUSA, A.C. }\end{array}$ & 2011 & UFF/UNIPLI \\
\hline
\end{tabular}

\section{Ciência e Educação (C\&Ed)}

A busca se deu na área do conhecimento: Ciências Exatas e da Terra, selecionando como subárea do conhecimento: Ciências Exatas e da Terra (Geral), obtendo 152 registros. Justifica-se a escolha deste periódico por reunir estudos de áreas de conhecimento como ciências biológicas, ciências humanas e ciências exatas e da terra. Foram pesquisados todos os artigos publicados de 2005 a 2011, totalizando 271 publicações (Tabela 1). Destas, 24 (8,9\%) corresponderam os critérios de inclusão, contendo as palavras/expressões: educação ambiental, ensino de ciências e/ou escola (Tabela 3). 
Tabela 3. Apresentação dos 24 artigos pesquisados no periódico C\&Ed.

\begin{tabular}{|c|c|c|c|}
\hline Título do Artigo & Autor(es) & Ano & Instituição \\
\hline $\begin{array}{c}\text { Meio ambiente, Escola e a formação dos } \\
\text { professores }\end{array}$ & $\begin{array}{l}\text { CHAVES, A.L.; } \\
\text { FARIAS, M.E. }\end{array}$ & 2005 & ULBRA \\
\hline $\begin{array}{c}\text { Coletores de lixo e enteroparasitoses: o papel } \\
\text { das representações sociais em suas atitudes } \\
\text { preventivas }\end{array}$ & NUNES et al. & 2006 & UFU-MG \\
\hline $\begin{array}{l}\text { Representações sobre meio ambiente de } \\
\text { alunos da quarta série do Ensino Fundamental }\end{array}$ & $\begin{array}{l}\text { MARTINHO, L.R. } \\
\text { TALAMONI, J.L.B. }\end{array}$ & 2007 & UNESP \\
\hline $\begin{array}{c}\text { O lugar e as escalas e suas dimensões } \\
\text { horizontal e vertical nos trabalhos práticos: } \\
\text { implicações para o ensino de ciências e } \\
\text { educação ambiental }\end{array}$ & COMPIANI, M. & 2007 & Unicamp \\
\hline $\begin{array}{c}\text { O direito ambiental na sala de aula: } \\
\text { significados de uma prática educativa no } \\
\text { ensino médio }\end{array}$ & $\begin{array}{l}\text { FARIAS, C.R.O.; } \\
\text { CARVALHO, W.L.P. }\end{array}$ & 2007 & UFSCar/UNESP \\
\hline $\begin{array}{l}\text { A construção coletiva interdisciplinar em } \\
\text { educação ambiental no ensino médio: a } \\
\text { microbacia hidrográfica do Ribeirão dos } \\
\text { Peixes como tema gerador }\end{array}$ & LUCATTO et al. & 2007 & UNESP \\
\hline $\begin{array}{l}\text { Produção coletiva de conhecimentos sobre } \\
\text { qualidade de vida: por uma educação } \\
\text { ambiental participativa e emancipatória }\end{array}$ & $\begin{array}{l}\text { JANKE, N.; TOZONI- } \\
\text { REIS, M.F.C. }\end{array}$ & 2008 & UNESP \\
\hline $\begin{array}{c}\text { Experimentação no ensino médio de química: } \\
\text { a necessária busca da consciênica ético- } \\
\text { ambiental no uso e descarte de produtos } \\
\text { químicos - um estudo de caso }\end{array}$ & $\begin{array}{l}\text { SILVA, R.R.; } \\
\text { MACHADO, P.F.L. }\end{array}$ & 2008 & UnB \\
\hline $\begin{array}{l}\text { Filmes de ficção científica como mediadores } \\
\text { de conceitos relativos ao meio ambiente }\end{array}$ & MACHADO, C.A. & 2008 & PUC-Rio \\
\hline $\begin{array}{l}\text { Contribuições para o trabalho com valores em } \\
\text { Educação Ambiental }\end{array}$ & BONOTTO, D.M.B. & 2008 & UNESP \\
\hline $\begin{array}{c}\text { O currículo de uma escola de formação } \\
\text { pedagógica e a dimensão ambiental: dilemas } \\
\text { entre teoria e práxis }\end{array}$ & ROSA et al. & 2008 & UEPB \\
\hline $\begin{array}{l}\text { As contribuições a partir do olhar atento: } \\
\text { estudos do meio e a educação para a vida }\end{array}$ & $\begin{array}{l}\text { LESTINGE, S.; } \\
\text { SORRENTINO, M. }\end{array}$ & 2008 & UnB \\
\hline $\begin{array}{l}\text { Explorando a bacia hidrográfica na escola: } \\
\text { contribuições à Educação Ambiental }\end{array}$ & $\begin{array}{l}\text { BERGMAN, M.; } \\
\text { PEDROZO, C.S. }\end{array}$ & 2008 & UFRGS \\
\hline $\begin{array}{l}\text { A pesquisa-ação em educação ambiental: } \\
\text { uma experiência no entorno de uma unidade } \\
\text { de conservação urbana }\end{array}$ & $\begin{array}{l}\text { CERATI, T.M.; } \\
\text { LAZARINI, R.A.M. }\end{array}$ & 2009 & $\begin{array}{l}\text { Instituto de } \\
\text { Botânica }\end{array}$ \\
\hline $\begin{array}{l}\text { Explorando conteúdos matemáticos a partir de } \\
\text { temas ambientais }\end{array}$ & LEITE et al. & 2009 & Puccamp \\
\hline
\end{tabular}




\begin{tabular}{|c|c|c|c|}
\hline $\begin{array}{c}\text { Educação ambiental e educação em valores em } \\
\text { livros didáticos de ciências naturais }\end{array}$ & $\begin{array}{c}\text { BONOTTO, D.M.B.; } \\
\text { SEMPREBONE, A. }\end{array}$ & 2010 & UNESP \\
\hline $\begin{array}{c}\text { A fotografia de natureza como instrumento para } \\
\text { educação ambiental }\end{array}$ & BORGES et al. & 2010 & UFPR \\
\hline $\begin{array}{c}\text { Percepção ambiental de crianças e pré- } \\
\text { adolescentes em vulnerabilidade social para } \\
\text { projetos de educação ambiental }\end{array}$ & PEDRINI et al. & 2010 & UERJ \\
\hline $\begin{array}{c}\text { Um panorama das pesquisas sobre livro } \\
\text { didático e educação ambiental }\end{array}$ & MARPICA, N.S.; & 2010 & UFSCar \\
\hline $\begin{array}{c}\text { Concepções e práticas de educação ambiental } \\
\text { de professores de uma escola pública }\end{array}$ & $\begin{array}{c}\text { VALENTIN, L.; SANTANA, } \\
\text { L.C. }\end{array}$ & 2010 & UNESP \\
\hline $\begin{array}{c}\text { Empresariado e ambiente: algumas } \\
\text { considerações sobre a educação ambiental no } \\
\text { espaço escolar }\end{array}$ & BAGNOLO, C.M. & 2010 & Unicamp \\
\hline $\begin{array}{c}\text { Ensino de ciências e educação ambiental no } \\
\text { nível fundamental: análise de algumas } \\
\text { estratégias didáticas }\end{array}$ & $\begin{array}{c}\text { NETO, A.L.G.C; AMARAL, } \\
\text { E.M.R. }\end{array}$ & 2011 & UFRP \\
\hline $\begin{array}{c}\text { Educação ambiental: reflexões sobre a prática } \\
\text { de um grupo de professores de química }\end{array}$ & $\begin{array}{c}\text { LEITE, R.F.; RODRIGUES, } \\
\text { M.A. }\end{array}$ & 2011 & UEM-PR \\
\hline $\begin{array}{c}\text { Representações sobre meio ambiente de } \\
\text { alunos da Educação Básica de Palmas (TO) }\end{array}$ & $\begin{array}{c}\text { AIRES, B.F.C.; BASTOS, } \\
\text { R.P. }\end{array}$ & 2011 & UFTO \\
\hline
\end{tabular}

\section{Pesquisa na Biblioteca Virtual de Saúde (BVS) utilizando a base de dados LILACS}

$\mathrm{Na}$ LILACS, o campo de pesquisa foi preenchido através das seguintes palavras/expressões: "ensino de ciências" ou "educação ambiental” e "escola" (Figura 1). Foram obtidas 23 referências mostradas sequencialmente em três páginas (Figura 2). No entanto, 09 (39\%) obedeceram aos critérios de inclusão, contendo as palavras/expressões: educação ambiental, ensino de ciências e/ou escola, e correspondendo ao período de 2005 a 2011. A tabela abaixo apresenta os 09 trabalhos obtidos após a busca na base de dados LILACS. Foi discriminado o tipo de estudo, resultando em 05 teses e 04 artigos. A grande maioria das publicações é oriunda da região sudeste, principalmente o estado de São Paulo. 
Tabela 4. Apresentação dos 09 estudos pesquisados na BVS através da LILACS.

\begin{tabular}{|c|c|c|c|c|}
\hline Título do Artigo & Autor(es) & Ano & Tipo & Fonte \\
\hline $\begin{array}{c}\text { Educadores ambientais nas escolas: as redes } \\
\text { como estratégia }\end{array}$ & GUIMARÃES et al. & 2009 & Artigo & Cad CEDES \\
\hline $\begin{array}{c}\text { Projeto coração roxo de biomonitoramento e } \\
\text { educaçáo ambiental: análise de uma } \\
\text { experiência com alunos de uma escola pública } \\
\text { no município de Cubatão SP }\end{array}$ & CAMPINA, N.N. & 2008 & Tese & USP \\
\hline $\begin{array}{c}\text { Interdisciplinaridade e meio ambiente: } \\
\text { caminhos que se cruzam }\end{array}$ & SANTOS, T.C. & 2008 & Tese & IOC \\
\hline $\begin{array}{c}\text { Educação ambiental na escola: ações } \\
\text { pedagógicas no contexto lixo-água-saúde }\end{array}$ & PEREIRA, E.G.C. & 2008 & Tese & IOC \\
\hline $\begin{array}{c}\text { Os "Vigilantes da Natureza" numa escola de } \\
\text { São Paulo }\end{array}$ & $\begin{array}{c}\text { SIQUEIRA, A.E.; } \\
\text { CARNEIRO, A.B. }\end{array}$ & 2008 & Artigo & BIREME \\
\hline $\begin{array}{c}\text { Educação, saúde, meio ambiente e políticas } \\
\text { públicas: o que pensam os professores? }\end{array}$ & MARQUES, E.P. & 2007 & Tese & USP \\
\hline $\begin{array}{c}\text { Os efeitos do turismo em Ilha Bela na } \\
\text { percepção da comunidade escolar }\end{array}$ & CORTEZ, J. & 2006 & Tese & USP \\
\hline $\begin{array}{c}\text { Educar na convivência: a experiência da } \\
\text { Escola Vila, em Fortaleza (CE) }\end{array}$ & NASCIMENTO, P.L. & 2006 & Artigo & Saúde Debate \\
\hline \begin{tabular}{c} 
Educação ambiental para uma escola saudável \\
\hline
\end{tabular} & PELICIONI, M.C.F. & 2005 & Artigo & USP \\
\hline
\end{tabular}

\section{DISCUSSÃO}

Apesar de apenas 26 artigos (6,3\%) terem sido encontrados nos periódicos IEC (2/143) e C\&Ed (24/271), respectivamente, de um universo de 414 artigos de ensino de ciências e 09 trabalhos encontrados na BVS, as questões socioambientais têm sido cada vez mais abordadas na escola em disciplinas de ciências naturais, como biologia, química e física, além de matemática e geografia. Martinho e Talamoni (2007) destacam a representação que os alunos do ensino fundamental têm sobre o meio ambiente, enfatizando a necessidade de desenvolvimento de ações educativas ambientalmente comprometidas com a formação de sujeitos ecológicos como defendido por Carvalho (2011).

A maioria dos estudos se concentrou na percepção dos alunos, através de ações educativas que possibilitassem uma eficácia na transferência dos conceitos ecológicos 
sobre diversos temas como saúde, turismo, ecossistema, políticas, valores, ética e cidadania.

Além disso, existe uma preocupação com o conteúdo de educação ambiental que está sendo ministrado nas escolas. Marpica e Logarezzi (2010) em estudo sobre a necessidade de um instrumento de apoio à abordagem da educação ambiental no contexto escolar apontaram várias deficiências encontradas nos livros didáticos e enfatizaram que as escolas devem adotar a perspectiva de uma educação ambiental problematizadora, crítica e transformadora.

\section{CONCLUSÃO}

Os resultados obtidos através da pesquisa nos periódicos IEC e C\&Ed, além da base de dados LILACS mostram como o tema educação ambiental possui relevância para o ensino de ciências. Muitos professores veem nos trabalhos de campo uma oportunidade para trazer as questões socioambientais para dentro de sala de aula. Foi observado o uso de métodos lúdicos e artísticos como formas de atrair a atenção dos alunos para o debate de problemas ambientais como poluição do ar e rios, aquecimento global, problema do lixo, enchentes e o uso indiscriminado da água. A análise dos artigos validou a idéia de inter e transdisciplinaridade no tratamento das questões ambientais nas escolas.

A problemática do lixo tem sido discutida nas escolas através de atividades de campo, oficinas e exposições sobre os riscos à saúde e suas consequências para o ambiente. Percebe-se ainda uma preocupação em associar educação ambiental às atividades de ensino de ciências e integrar esse tema na prática pedagógica dos professores, respeitando-se o contexto dos alunos. Alguns autores assumem uma postura notadamente crítica em relação à forma como os alunos são influenciados pela sociedade de consumo desordenado, além de chamarem atenção para o risco de doenças e degradação ambiental em decorrência da destinação inadequada de resíduos sólidos no ambiente.

O estudo mostra que a educação ambiental vem se destacando no campo da pesquisa de maneira inter e pluridisciplinar, podendo, além disso, servir de base para a criação de projetos político-pedagógicos, que auxiliem no debate de questões socioambientais e contribuam para uma educação comprometida com o desenvolvimento sustentável. 


\section{REFERÊNCIAS}

AIRES, B.F.C.; BASTOS, R.P. Representações sobre meio ambiente de alunos da Educação Básica de Palmas (TO). Ciência \& Educação (Bauru) vol.17 no.2 Bauru; 2011.

BAGNOLO, C.M. Empresariado e ambiente: algumas considerações sobre a educação ambiental no espaço escolar. Ciência \& Educação (Bauru) vol.16 no.2 Bauru; 2010.

BERGMAN, M.; PEDROZO, C.S. Explorando a bacia hidrográfica na escola: contribuições à Educação Ambiental. Ciência \& Educação (Bauru) vol.14 no.3 Bauru; 2008.

BONOTTO, D.M.B. Contribuições para o trabalho com valores em Educação Ambiental. Ciência \& Educação (Bauru) vol.14 no.2 Bauru; 2008.

BONOTTO, D.M.B.; SEMPREBONE, A. Educação ambiental e educação em valores em livros didáticos de ciências naturais. Ciência \& Educação (Bauru) vol.16 no.1 Bauru; 2010.

BORGES, M.D.; ARANHA, J.M.; SABINO, J. A fotografia de natureza como instrumento para educação ambiental. Ciência \& Educação (Bauru) vol.16 no.1 Bauru; 2010 .

CAMPINA, N.N. Projeto coração roxo de biomonitoramento e educação ambiental: análise de uma experiência com alunos de uma escola pública no município de Cubatão SP [Tese]. São Paulo. Faculdade de Medicina. Universidade de São Paulo. 2008. 128 p.

CAMPOS, S.S.P.; CAVASSAN, O. A oficina de materiais recicláveis no ensino de ciências e nos programas de educação ambiental: refletindo sobre a prática educativa. Anais do VI Encontro Nacional de Pesquisa em Educação em Ciências (ENPEC). Disponível em: http://www.fae.ufmg.br/abrapec/viempec/viempec/entrar.html. Acesso em 20/12/11

CARVALHO, Isabel Cristina de Moura. Educação ambiental: a formação do sujeito ecológico. $5^{\text {a }}$ Ed. São Paulo. Ed. Cortez; 2011.

CERATI, T.M.; LAZARINI, R.A.M. A pesquisa-ação em educação ambiental: uma experiência no entorno de uma unidade de conservação urbana. Ciência \& Educação (Bauru) vol.15 no.2 Bauru; 2009.

CHAVES, A.L.; FARIAS, M.E. Meio ambiente, Escola e a formação dos professores. Ciência \& Educação (Bauru) vol.11 no.1 Bauru Jan./Apr. 2005.

COMPIANI, M. O lugar e as escalas e suas dimensões horizontal e vertical nos trabalhos práticos: implicações para o ensino de ciências e educação ambiental. Ciência \& Educação (Bauru) vol.13 no.1 Bauru Jan./Apr. 2007.

CORTEZ. J. Os efeitos do turismo em Ilha Bela na percepção da comunidade escolar [Tese]. São Paulo. Universidade de São Paulo; s.n; 2006. 209 p. 
DAMASIO, M.L.L.; SAMPAIO, A.C. As representações sociais do lixo: Subsídios para a educação do consumidor. In: Educação ambiental: da prática pedagógica à cidadania. Jandira L.B. Talamoni, Aloísio Costa Sampaio, organizadores. - São Paulo: Escrituras Editora, 2003.

FARIAS, C.R.O.; CARVALHO, W.L.P. O direito ambiental na sala de aula: significados de uma prática educativa no ensino médio. Ciência \& Educação (Bauru) vol.13 no.2 Bauru May/Aug. 2007.

FERREIRA, N.S.A. As pesquisas denominadas "Estado da Arte". Educação \& Sociedade, ano XXIII, no 79, Agosto/2002.

FRACALANZA, H. As pesquisas sobre educação ambiental no Brasil e as escolas: alguns comentários preliminares. In: TAGLIEBER, J.E.; GUERRA, A.F.S. (org.) Pesquisa em Educação Ambiental: pensamentos e reflexões. I Colóquio de Pesquisadores em EA. Pelotas: Ed. Universitária/UFPEL; 2004.

GUIMARAES, Mauro et al . Educadores ambientais nas escolas: as redes como estratégia. Cad. CEDES, Campinas, v. 29, n. 77, abr. 2009 . Disponível em $<\mathrm{http}: / / \mathrm{www}$.scielo.br/scielo.php?script=sci_arttext\&pid=S0101$32622009000100004 \& \operatorname{lng}=$ pt\&nrm=iso >. Acesso em 15 dez. 2011.

GUIMARÃES, M.; VASCONCELLOS, M. das M. N. Relações entre educação ambiental e educação em ciências na complementaridade dos espaços formais $e$ não formais de educação. Educar, Curitiba, n. 27, p. 147-162. Editora UFPR; 2006.

GUSMÃO et al. Reciclagem artesanal na UEFS: estratégia educacional na valorização do meio ambiente. In: CONGRESSO NACIONAL DE MEIO AMBIENTE NA BAHIA, 2., 2000. Salvador. Anais... Salvador: UFBA, 2000. p 56-58.

JANKE, N.; TOZONI-REIS, M.F.C. Produção coletiva de conhecimentos sobre qualidade de vida: por uma educação ambiental participativa e emancipatória. Ciência \& Educação (Bauru) vol.14 no.1 Bauru; 2008.

LATINI, R.M.; SOUSA, A.C. Ensino de Química e Ambiente: As articulações presentes na revista Química Nova na Escola (Qnesc). Investigações em Ensino de Ciências - V16(1), pp. 143-159, 2011.

LEITE, M.B.F.; FERREIRA, D.H.L.; SCRICH, C.R. Explorando conteúdos matemáticos a partir de temas ambientais. Ciência \& Educação (Bauru) vol.15 no.1 Bauru; 2009.

LEITE, R.F.; RODRIGUES, M.A. Educação ambiental: reflexões sobre a prática de um grupo de professores de química. Ciência \& Educação (Bauru) vol.17 no.1 Bauru; 2011.

LESTINGE, S.; SORRENTINO, M. As contribuições a partir do olhar atento: estudos do meio e a educação para a vida. Ciência \& Educação (Bauru) vol.14 no.3 Bauru; 2008. 
LUCATTO, L.G.; TALAMONI, J.L.B. A construção coletiva interdisciplinar em educação ambiental no ensino médio: a microbacia hidrográfica do Ribeirão dos Peixes como tema gerador. Ciência \& Educação (Bauru) vol.13 no.3 Bauru Sept./Dec. 2007.

MACHADO, C.A. Filmes de ficção científica como mediadores de conceitos relativos ao meio ambiente. Ciência \& Educação (Bauru) vol.14 no.2; Bauru; 2008.

MARPICA, N.S.; LOGAREZZI, A.J.M. Um panorama das pesquisas sobre livro didático e educação ambiental. Ciência \& Educação (Bauru) vol.16 no.1 Bauru; 2010.

MARQUES, E. P. Educação, Saúde, Meio Ambiente e Políticas Públicas: o que pensam os professores? Dissertação (Mestrado) - Universidade de São Paulo Faculdade de Saúde Pública. São Paulo, 2007.

MARTINHO, L.R.; TALAMONI, J.L.B. Representações sobre meio ambiente de alunos da quarta série do Ensino Fundamental. Ciência \& Educação (Bauru) vol.13 no.1 Bauru Jan./Apr. 2007.

NASCIMENTO, P. L. . Educar na convivência: a experiência da Escola Vila em Fortaleza-CE. Divulgação em Saúde para Debate, v. 1, p. 100-108, 2006.

NETO, A.L.G.C; AMARAL, E.M.R. Ensino de ciências e educação ambiental no nível fundamental: análise de algumas estratégias didáticas. Ciência \& Educação (Bauru) vol.17 no.1 Bauru; 2011.

NUNES, A.L.B.P.; CUNHA, A.M.O.; JUNIOR, O.M. Coletores de lixo e Enteroparasitoses: o papel das representações sociais em suas atitudes preventivas. Ciência \& Educação (Bauru) vol.12 no.1 Bauru Jan./Apr. 2006

PEDRINI, A.; COSTA, E.A.; GHILARDI, N. Percepção ambiental de crianças e préadolescentes em vulnerabilidade social para projetos de educação ambiental. Ciência \& Educação (Bauru) vol.16 no.2 Bauru; 2010.

PELICIONI, M.C.F. Educação Ambiental para uma Escola Saudável. In: Phillipi Jr., A; Pelicioni, M.C.F. (eds.). Educação Ambiental e Sustentabilidade. Barueri, SP:

Manole, 2005.

PEREIRA, E.G.C. Educação ambiental na escola: ações pedagógicas no contexto lixo-água-saúde. Dissertação (Mestrado). Instituto Oswaldo Cruz. Ensino em Biociências e Saúde. 2008. 128 p.

RODRIGUES, DCGA. Ensino de Ciências e a Educação Ambiental. Revista Práxis. ano I, $\mathrm{n}^{\mathrm{o}} 1$ - janeiro; 2009.

RODRIGUES, L.L.; FARRAPEIRA, C.M.R. Percepção e educação ambiental sobre o ecossistema Manguezal incrementando as disciplinas de Ciências e Biologia em escola pública do Recife-PE. Investigações em Ensino de Ciências - V13(1), pp.79-93, 2008. 
ROSA, L.G.; LEITE, V.D. SILVA, M.M.P. O currículo de uma escola de formação pedagógica e a dimensão ambiental: dilemas entre teoria e práxis. Ciência \& Educação (Bauru) vol.14 no.3 Bauru; 2008.

SANTOS, T.C. Interdisciplinaridade e Meio Ambiente: caminhos que se Cruzam. Rio de Janeiro 2008, disponível em: http://bases.bireme.br/cgibin/wxislind.exe/iah/online/ acesso em: 10 dez 2011.

SILVA, R.R.; MACHADO, P.F.L. Experimentação no ensino médio de química: a necessária busca da consciência ético-ambiental no uso e descarte de produtos químicos - um estudo de caso. Ciência \& Educação (Bauru) vol.14 no.2 Bauru; 2008.

SIQUEIRA, A.E.; CARNEIRO, A.B. Os "Vigilantes da Natureza" numa escola de São Paulo. Estudos avançados. vol.22 no.63 São Paulo; 2008.

VALENTIN, L.; SANTANA, L.C. Concepções e práticas de educação ambiental de professores de uma escola pública. Ciência \& Educação (Bauru) vol.16 no.2 Bauru; 2010. 